\title{
Risk Analysis and Management in Software Engineering
}

\author{
I. MaryLinda, S.Kavitha, S. Theivasigamani
}

\begin{abstract}
Many programming building ventures have high dangers and disappointment rates amid their undertaking life. The undertakings primarily experience the ill effects of dangers created in programming advancement which are for the most part caused by operational dangers, innovative dangers, administration rehearses, hazards in accomplishing client acknowledgment of the item and business dangers. Hazard can be decreased with certain work process ventures for the product venture. Typically, hazard administration exist anytime of time when a client breaks down and endeavors to evaluate the vital dangers for misfortunes in a speculation and afterward takes those suitable activities to their venture targets and hazard resistance. Disgraceful hazard administration may bring about extreme punishment for the two organizations and clients. The point of this paper is to diminish the key dangers of programming building ventures in the event that we keep up appropriate work process ventures in every improvement phases of programming designing activities which brings about guarantee venture achievement.

Keywords: chance administration, programming designing, dangers examination, dangers, programming improvement life cycle, programming venture administration.
\end{abstract}

\section{INTRODUCTION}

Hazard is a vulnerability that can have a negative or constructive outcome on meeting venture goals. Hazard administration is the way toward recognizing, examining, and controlling danger for the duration of the life of a venture to meet the task destinations [1,2]. The product building forms is characterized as the interdisciplinary assignments that are required all through a product item's life cycle to change client needs, prerequisites, and limitations into a framework arrangement $[3,4]$. Overseeing Risk is having two stage process specifically, one is recognizing dangers associated with a venture and other is taking care of those dangers to get the task objectives [5, 6]. Hazard components ought to be viewed as legally binding danger, specialized dangers, operational hazard, chances because of size and intricacy of the item, business risks $[7,8]$. The field of programming advancement frequently experiences numerous sorts of dangers with high disappointment rate which thus impact the achievement of programming venture $[9,10]$.

Revised Manuscript Received on July 22, 2019.

I.MaryLinda, Department of CSE, Bharath Institute of Higher Education and Research, Chennai, Tamilnadu, India.

S.Kavitha*, Department of CSE, Bharath Institute of Higher Education and Research, Chennai, Tamilnadu, India.

S. Theivasigamani, Department of CSE, Bharath Institute of Higher Education and Research, Chennai, Tamilnadu, India.

\section{LITERATURE REVIEW}

Tummala and Leung (1999) has created a technique for hazard administration winning danger ID, estimation, appraisal, assessment and hazard control and checking for use of overseeing cost chance for an EHV transmission line venture [11].

Freimut et al. (2001) has featured usage of programming hazard administration for mechanical contextual investigation. The outcomes showed that the hazard technique is trial, esteem expansion to the product undertaking, and key ideas are comprehended and usable by and by [12].

Padayachee (2002) featured a field examination structure for hazard administration for a specific programming improvement organization. It was basically tried for a few organizations [13].

Flinn and Stoyles (2004) proposed chance administration wonders for building trust and certainty for the Internet clients [14].

Huang et al. (2004) has featured a hazard prioritization technique by utilizing logical chain of command process for big business asset arranging usage and the recommended structure considers both subjective and quantitative components. The examination builds up a coordinated structure approach for overseeing dangers in programming advancement of an association inside the Government of Barbados [15].

Baccarini et al. (2004) had recognized and concerned IT anticipate hazards by experimental research and proposed conceivable reactions with no system for programming hazard administration [16].

Redzic, et al. (2006) offered Six Sigma DMAIC approach utilized for programming quality change of programming items. In view of information investigation, specialists had chosen to actualize new advancements (instruments, techniques, measures, and preparing) to achieve venture objective [17].

Khanfar, et al. (2008) featured that for the achievement of programming ventures is relies upon inclusion of various control factors and diverse programming hazard factors which utilizes chi-square test to control the dangers in a product venture [18].

Zheng, et al. (2009) anticipated an estimation technique for programming exertion in light of capacity focuses by utilizing the straight relations between work focuses and programming endeavors [19].

Hribar, et al (2009) featured on 
programming quality positions (SQR) a vital technique to oversee and enhance programming quality short improvement lifecycles [20].

Alshathry and Anicke (2010) anticipated a relapse based model which permits venture chiefs to evaluate the exchange off among quality cost and improvement time of a product advancement item [21].

Guoheng, et al. (2010) featured an Analytic Hierarchical Process (AHP) marvels to appraise the relative significance of each utilitarian variable component on a quality trait [22].

Bukhari and Arif (2010) stressed a multi-specialist system to help the quality supervisor to accomplish quality goals of the product item [23].

Lincke, et al. (2010) framed factually analyzed quality models which have beforehand been determined in observational investigations by applying them to programming frameworks. In this way in this investigation, a legitimate work process ventures for programming advancement process are proposed to lessen dangers and disappointment rates in programming building ventures [24, 25].

\section{LEVEL OF RISK IN DIFFERENT STAGES OF SOFTWARE ENGINEERING PROJECT'S LIFE CYCLE}

In any product advancement process, there are sure odds of hazard however level of hazard may change at the diverse phases of programming improvement life cycle. At first level i.e programming prerequisite investigation, odds of hazard is less in light of the fact that it is essential level of programming improvement life cycle [26, 27]. Level of hazard in programming improvement stages will increment alongside the advancement stages (outline, coding, testing\& Integration) of the product (Figure 1). A high possibility of hazard in programming happens at the product improvement. On the off chance that appropriate work process steps are taken after amid every phase of programming advancement life cycle, at that point level of hazard can be limited. So programming designer ought to distinguish, break down, design, check, control for each of the key hazard related with the diverse phases of programming advancement life cycle [28, 29].

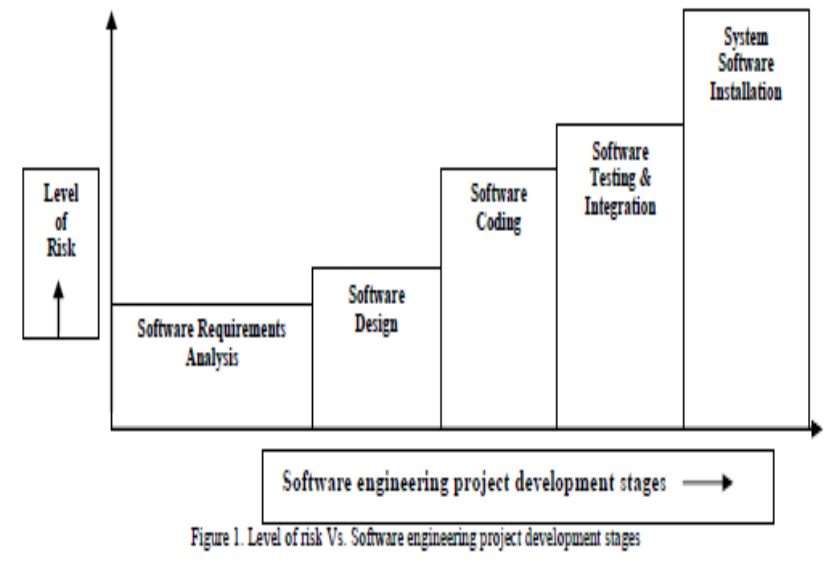

\section{RESULTS AND DISCUSSION}

\section{A. Programming investigation}

At the point when an outside client gives their necessities to extend group, the group dissects programming prerequisites for every product thing. Every product thing comprises of various programming segments. The product thing incorporates the practical and ability determinations, execution, and outer interfaces to the framework, capability necessities, information definition, database prerequisites, establishment and acknowledgment prerequisites of the conveyed programming item, client documentation, client activity and execution necessities. The product necessities should be assessed for the traceability to the framework prerequisites and framework plan, outer consistency with framework necessities, inner consistency, testability, and plausibility of programming outline [30, 31].

The information necessity for programming prerequisite investigation is programming engineering, interface configuration record, framework compositional outline. At that point programming designer will create programming prerequisite investigation (SRA) report for the product building venture. The product test group and programming module designer will do test and approval design (TVPL) in view of programming necessity record. Programming audit group will do programming necessities survey through minutes of meeting (MOM) which conveys MOM, consistence explanation, programming change proposition for parent report, standard programming prerequisite examination archive [32,33].

\section{B. Programming outline}

Programming engineer will take after two stages of programming plan to be specific preparatory outline and point by point plan. Programming preparatory outline step involve change of the prerequisites for the product thing into design that depict its best level structure and distinguishes the product segments. It might be guaranteed that every one of the prerequisites for the product thing are dispensed to its product parts and further refined to encourage point by point outline [34, 35]. An archive to portray the best level 
outline for the interface outside to the product thing, preparatory test prerequisites and timetable for programming joining might be created. The product engineering should be assessed for the traceability to the product necessities, outer consistency with the product prerequisites, inward consistency between the product parts, fittingness of plan techniques and principles utilized practicality of nitty gritty outline. The activities imagines building up the rules for top level programming engineering outline for auxiliary and protest situated plan approach, tailor the format of best level engineering archive and give agenda to top level plan survey $[36,37]$.

Programming point by point Design includes this stage includes advancement an itemized plan for every product part of the product thing. The product segments might be refined into bring down levels containing programming units that can be coded, ordered and tried.

It might be guaranteed that all the product necessities are dispensed from the product parts to programming units. A record on nitty gritty plan for the interface outer to the product thing, between the product parts and between the product units, test prerequisites and calendar for testing programming units would be created. The point by point outline of the interfaces might allow coding without the requirement for additional data. The product point by point configuration might be assessed for the traceability to the necessities of the product thing, outside consistency with the engineering outline, inner consistency between programming segments and programming units, testability, plausibility of testing, activity and support.

In view of $\mathrm{SRD}$, the product module designer will do programming plan which conveys SAD, SCP for parent archive. The product test group will do programming test plan which gives test and approval strategy (TVPR) record to programming module designer. Programming audit group will do programming configuration survey which conveys MOM, consistence explanation, SCP for parent archive, gauge SRD [38]

\section{Programming coding}

- In this stage, the engineer for every product thing might create programming unit and database, test methods and information for testing every product unit and database.. The product code and test outcomes should be assessed in view of the criteria of traceability to the prerequisites and plan of the product thing, outside consistency with the necessities and outline of the product thing, interior consistency between unit necessities, test scope of the units, suitability of coding strategies and guidelines utilized, possibility of programming Integration and testing.

- The Software Module Developer will do PC programming unit (CSU) level coding in view of Software design report and programming coding rules which conveys CSCI Code, Test Driver Code, SCP for parent archive. The Software Module Developer will do CSU level testing which is called unit testing [39]

\section{Programming testing and coordination}

In this stage, the engineer should test every product unit and database, refresh the client documentation, test necessities and calendar for programming joining. The engineer should build up a mix intend to incorporate the product units and programming segments into the product thing. The arrangement should incorporate test necessities, strategies, information, duties and calendar. The designer should incorporate the product units and programming segments and test as the totals are created as per the combination design. This stage includes leading capability testing as per the capability necessities for the product thing. It might be guaranteed that the usage of every product necessities is tried for consistence. The designer should assess configuration, code, tests, and test outcomes thinking about the criteria for test scope of the prerequisites of the product thing, conformance to the normal outcomes, attainability of framework mix and testing. The designer should bolster the review and after finishing of the review refresh the deliverable programming items and build up a gauge for the plan and code of the product thing. The undertaking conceives to list down the exercises to be done by the engineer amid this stage.

The product test group (Internal) will do PC programming setup thing (CSCI) movement in light of SCPs, SRD, TVPL, TVPR, IDD, CSCI Code, and Test Driver to deliver CSCI test comes about. The product module designer will do CSCI imperfection determination in view of CSCI test comes about, SRD, SAD, TVPL, TVPR, IDD. The framework test group (interior)/framework audit group will do combination test arranging/survey movement in view of SyRS, SARAD, Sw. engineering/ITP record.

\section{E. Framework programming establishment}

The product design things might be coordinated with equipment arrangement thing, manual activities and different frameworks as vital, into the framework. The combination and test outcomes might be recorded. For every capability prerequisite of the framework, an arrangement of test, test cases and test technique for directing framework capability testing might be produced and archived. The coordinated framework should be assessed in light of the criteria for the test scope of framework necessities, fittingness conformance to expected outcomes, and attainability of framework capability testing.

There are distinctive kinds of dangers related in programming advancement, for example, operational dangers, specialized dangers, administration hones, and operational dangers. The operational dangers are: dangers of misfortune because of dishonorable process usage, fizzled framework or some outside occasions dangers. Administration rehearses Risk incorporates wrong spending estimation, cost overwhelms, time invades, venture scope extension. Specialized dangers related with disappointment of usefulness and execution [40]. 
The benefits of overseeing hazard are sparing assets, human, wage, property, framework, cost, time [3]. It likewise ensures condition, open picture and forestalls/lessens legitimate obligation. An arrangement to introduce the product item in the objective condition as assigned in the agreement to help the designer should introduce the product item. The assets and data important to introduce the product item might be resolved and be accessible.

The framework acknowledgment test group (outside client) will do framework establishment testing which conveys framework test comes about (outer). The framework programming incorporation group will do framework abandon separation that outcomes CSCI insightful imperfection assignment. The product module designer will do CSCI imperfection determination action which finishes framework programming establishment [41].

SRD: Software Requirement Document, SCP: Software Change Proposal, IDD: Interface Design Document, SARAD: System Architecture Design, TVPL: Test and Validation Plan, MOM: Minutes of Meeting, CSCI: Computer Software Configuration Item, SAD: Software Architectural Design, TVPR:

Test and Validation Procedure Report, SyRS: System Requirement Specification, ITP: Integration Test Plan, Sw: Software, Doc: Document, CSU: Computer Software Unit.

\section{CONCLUSION}

For this examination, it is reasoned that, the accompanying five noteworthy work process ventures to be taken care while being developed phases of programming building ventures so the product dangers can be figured out how to make extend progress.

\section{REFERENCES}

[1] Kumaravel A., Rangarajan K.,Algorithm for automaton specification for exploring dynamic labyrinths,Indian Journal of Science and Technology,V-6,I-SUPPL5,PP-4554-4559,Y-2013

[2] P. Kavitha, S. Prabakaran "A Novel Hybrid Segmentation Method with Particle Swarm Optimization and Fuzzy C-Mean Based On Partitioning the Image for Detecting Lung Cancer" International Journal of Engineering and Advanced Technology (IJEAT) ISSN: 2249-8958, Volume-8 Issue-5, June 2019

[3] Kumaravel A., Meetei O.N.,An application of non-uniform cellular automata for efficient cryptography,2013 IEEE Conference on Information and Communication Technologies, ICT 2013,V-,I-,PP-1200-1205,Y-2013

[4] Kumarave A., Rangarajan K.,Routing alogrithm over semi-regular tessellations,2013 IEEE Conference on Information and Communication Technologies, ICT 2013,V-,I-,PP-1180-1184,Y-2013

[5] P. Kavitha, S. Prabakaran "Designing a Feature Vector for Statistical Texture Analysis of Brain Tumor" International Journal of Engineering and Advanced Technology (IJEAT) ISSN: 2249-8958, Volume-8 Issue-5, June 2019

[6] Dutta P., Kumaravel A.,A novel approach to trust based identification of leaders in social networks,Indian Journal of Science and Technology,V-9,I-10,PP--,Y-2016

[7] Kumaravel A., Dutta P.,Application of Pca for context selection for collaborative filtering,Middle - East Journal of Scientific Research,V-20,I-1,PP-88-93,Y-2014

[8] Kumaravel A., Rangarajan K.,Constructing an automaton for exploring dynamic labyrinths,2012 International Conference on Radar, Communication and Computing, ICRCC 2012,V-,I-,PP-161-165,Y-2012
[9] P. Kavitha, S. Prabakaran "Adaptive Bilateral Filter for Multi-Resolution in Brain Tumor Recognition" International Journal of Innovative Technology and Exploring Engineering (IJITEE) ISSN: 2278-3075, Volume-8 Issue-8 June, 2019

[10]Kumaravel A.,Comparison of two multi-classification approaches for detecting network attacks, World Applied Sciences Journal,V-27,I-11,PP-1461-1465,Y-2013

[11]Tariq J., Kumaravel A.,Construction of cellular automata over hexagonal and triangular tessellations for path planning of multi-robots,2016 IEEE International Conference on Computational Intelligence and Computing Research, ICCIC 2016,V-,I-,PP--,Y-2017

[12]Sudha M., Kumaravel A.,Analysis and measurement of wave guides using poisson method,Indonesian Journal of Electrical Engineering and Computer Science,V-8,I-2,PP-546-548,Y-2017

[13]Ayyappan G., Nalini C., Kumaravel A.,Various approaches of knowledge transfer in academic social network, International Journal of Engineering and Technology,V-,I-,PP-2791-2794,Y-2017

[14]Kaliyamurthie, K.P., Sivaraman, K., Ramesh, S. Imposing patient data privacy in wireless medical sensor networks through homomorphic cryptosystems 2016, Journal of Chemical and Pharmaceutical Sciences92.

[15]Kaliyamurthie, K.P., Balasubramanian, P.C. An approach to multi secure to historical malformed documents using integer ripple transfiguration 2016 Journal of Chemical and Pharmaceutical Sciences92.

[16]A.Sangeetha,C.Nalini,"Semantic Ranking based on keywords extractions in the web", International Journal of Engineering \& Technology, 7 (2.6) (2018) 290-292

[17]S.V.GayathiriDevi,C.Nalini,N.Kumar,"An efficient software verification using multi-layered software verification tool "International Journal of Engineering \& Technology, 7(2.21)2018 454-457

[18]C.Nalini,ShwtambariKharabe,"A Comparative Study On Different Techniques Used For Finger - Vein Authentication", International Journal Of Pure And Applied Mathematics, Volume 116 No. 82017 327-333, Issn: 1314-3395

[19]M.S. Vivekanandan and Dr. C. Rajabhushanam, "Enabling Privacy Protection and Content Assurance in Geo-Social Networks", International Journal of Innovative Research in Management, Engineering and Technology, Vol 3, Issue 4, pp. 49-55, April 2018.

[20]Dr. C. Rajabhushanam, V. Karthik, and G. Vivek, "Elasticity in Cloud Computing", International Journal of Innovative Research in Management, Engineering and Technology, Vol 3, Issue 4, pp. 104-111, April 2018.

[21]K. Rangaswamy and Dr. C. Rajabhushanamc, "CCN-Based Congestion Control Mechanism In Dynamic Networks", International Journal of Innovative Research in Management, Engineering and Technology, Vol 3, Issue 4, pp. 117-119, April 2018.

[22]Kavitha, R., Nedunchelian, R., "Domain-specific Search engine optimization using healthcare ontology and a neural network backpropagation approach", 2017, Research Journal of Biotechnology, Special Issue 2:157-166

[23]Kavitha, G., Kavitha, R., "An analysis to improve throughput of high-power hubs in mobile ad hoc network" , 2016, Journal of Chemical and Pharmaceutical Sciences, Vol-9, Issue-2: 361-363

[24]Kavitha, G., Kavitha, R., "Dipping interference to supplement throughput in MANET", 2016, Journal of Chemical and Pharmaceutical Sciences, Vol-9, Issue-2: 357-360

[25]Michael, G., Chandrasekar, A.,"Leader election based malicious detection and response system in MANET using mechanism design approach", Journal of Chemical and Pharmaceutical Sciences(JCPS) Volume 9 Issue 2, April - June 2016 .

[26]Michael, G., Chandrasekar, A.,"Modeling of detection of camouflaging worm using epidemic dynamic model and power spectral density", Journal of Chemical and Pharmaceutical Sciences(JCPS) Volume 9 Issue 2, April - June 2016.

[27]Pothumani, S., Sriram, M., Sridhar, J., Arul Selvan, G., Secure mobile agents communication on intranet,Journal of Chemical and Pharmaceutical Sciences, volume 9, Issue 3, Pg No S32-S35, 2016

[28]Pothumani, S., Sriram, M., Sridhar , Various schemes for database encryption-a survey, Journal of Chemical and Pharmaceutical Sciences, volume 9, Issue 3, Pg NoS103-S106, 2016

[29]Pothumani, S., Sriram, M., Sridhar, A novel economic framework for cloud and grid computing, Journal of Chemical and Pharmaceutical Sciences, volume 9, Issue 3, Pg No S29-S31, 2016

[30]Priya, N., Sridhar, J., Sriram, M. "Ecommerce Transaction Security Challenges and Prevention Methods- New Approach" 2016 ,Journal of Chemical and Pharmaceutical Sciences, JCPS Volume 9 Issue 3.page no:S66-S68 .

[31]Priya, N.,Sridhar,J.,Sriram, M."Vehicular cloud computing

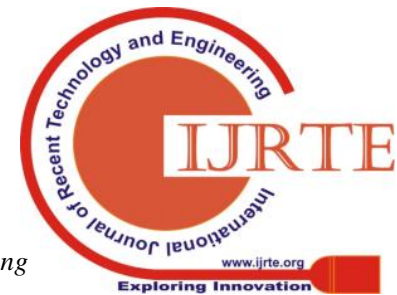


security issues and solutions" Journal of Chemical and Pharmaceutical Sciences(JCPS) Volume 9 Issue 2, April - June 2016

[32]Priya, N., Sridhar, J., Sriram, M. "Mobile large data storage security in cloud computing environment-a new approach” JCPS Volume 9 Issue 2. April - June 2016

[33]Anuradha.C, Khanna.V, "Improving network performance and security in WSN using decentralized hypothesis testing "Journal of Chemical and Pharmaceutical Sciences(JCPS) Volume 9 Issue 2, April - June 2016.

[34]Anuradha.C, Khanna.V, "A novel gsm based control for e-devices" Journal of Chemical and Pharmaceutical Sciences(JCPS) Volume 9 Issue 2, April - June 2016 .

[35]Anuradha.C, Khanna.V, "Secured privacy preserving sharing and data integration in mobile web environments " Journal of Chemical and Pharmaceutical Sciences(JCPS) Volume 9 Issue 2, April - June 2016.

[36]Sundarraj, B., Kaliyamurthie, K.P. Social network analysis for decisive the ultimate classification from the ensemble to boost accuracy rates 2016 International Journal of Pharmacy and Technology

[37]Sundarraj, B., Kaliyamurthie, K.P. A content-based spam filtering approach victimisation artificial neural networks 2016 International Journal of Pharmacy and Technology83.

[38]Sundarraj, B., Kaliyamurthie, K.P. Remote sensing imaging for satellite image segmentation 2016 International Journal of Pharmacy and Technology8 3

[39]Sivaraman, K., Senthil, M. Intuitive driver proxy control using artificial intelligence 2016 International Journal of Pharmacy and Technology84.

[40]Sivaraman, K., Kaliyamurthie, K.P. Cloud computing in mobile technology 2016 Journal of Chemical and Pharmaceutical Sciences92.

[41]Sivaraman, K., Khanna, V. Implementation of an extension for browser to detect vulnerable elements on web pages and avoid click jacking 2016 Journal of Chemical and Pharmaceutical Sciences92.

\section{AUTHORS PROFILE}

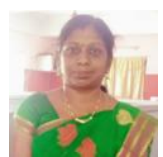

S. Kavitha, Associate Professor, Department of Computer Science \& Engineering, Bharath Institute of Higher Education and Research, Chennai, India

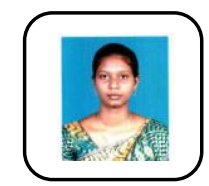

I.MaryLinda Assistant Professor, Department of Computer Science \& Engineering, Bharath Institute of Higher Education and Research, Chennai, India

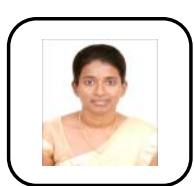

S. Theivasigamani Assistant Professor, Department of Computer Science \& Engineering, Bharath Institute of Higher Education and Research, Chennai, India 